\title{
Coughing from Copiers? Workplace Induced Chronic Cough after Exposure to Laser Printer Exhaust
}

\section{Alessandra D'Alessandro' ${ }^{1 *}$, Nadine Waldburg ${ }^{2}$, Irina Boeckelmann ${ }^{1}$ and Jens Schreiber ${ }^{2}$}

${ }^{1}$ Section of Occupational and Environmental Medicine, University Hospital of the Otto-von-Guericke-University Magdeburg, Germany

${ }^{2}$ Department of Pneumonology, University Hospital of the Otto-von-Guericke-University Magdeburg, Germany

\begin{abstract}
Despite an increasing number of patients complaining of respiratory symptoms when working with photocopiers and laser printers, the health hazards posed by these machines are considered to be minimal to non-existent. We report a patient employed as a governmental clerk who reported acute respiratory discomfort and cough occurring after an accidental exposure to toner dust while changing a cartridge. After the accident she reported dry cough and discomfort each time she used a laser printer. Since the symptoms were limiting her ability to work, she sought medical help. We performed lung function test before and after an occupational exposure to laser printer by having the patient copy documents for one hour. After the occupational exposure, the patient suffered chest discomfort and cough and although we did not observed changes in the pulmonary function, we did observe bronchial inflammatory changes, with increase of the neutrophilic component in BAL cellularity and sign of inflammation at the bronchial wall.
\end{abstract}

Abbreviations: BAL: Bronchoalveolar Lavage; TRP: Transient Receptor Potential; VOC: Volatile Organic Compounds

\section{Introduction}

Modern laser printers and copiers can emit dust and aereosol during operation and maintenance. To understand how emission can be generated we briefly review the principle of operation of common printing devices and provide a brief description of some of the common pollutant generated by printing devices.

A photoconductive surface (drum) inside the copiers is given a positive electrical charge through a corona wire. An intense beam of light moves across the paper placed on the copier's glass surface. Light is reflected only from the white areas of the paper and strikes the photoconductive surface below. Because the illuminated sections (the non-image areas) become more conductive, the charge dissipates in the exposed areas, so that a positive charge remains only at the site of image areas. When negatively charged powder (toner), is spread over the surface of the drum, it adheres through electrostatic attraction only to the positively charged image areas. When positively charged paper rolls over the drum, the negatively charged powder is attracted to the paper. Finally, the paper with toner particles on its surface travels between two fuser rolls that press the toner particle onto the paper surface, at the same time the rolls are heated up to $170^{\circ} \mathrm{C}$ to melt the toner particles and fuse the pigment to the paper, producing a copy of the original image (Figure 1) [1,2].

Chamber investigations and indoor air measurements which determined emissions of laser printers and photocopiers have shown that fine and ultrafine particles, gases such as ozone and various volatile organic compounds (VOC, SVOC) are released into indoor air and therefore, an exposure to complex mixtures consisting of particles and chemical compounds can be assumed while operating office machines [1].

Ozone gas is emitted during printing operation as a by-product of the electrophotographic process. The primary source of ozone is the corona wire. Therefore laser printers of the new generation that operate without a corona wire should, according to the producers, emit a negligible amount of ozone gas. However, investigation in experimental chambers, have shown that also the printers of the latest generation can emit Ozone [3]. VOC and SVOC can be generated in the process of fusing when the paper with toner particles on its surface is heated up.
Moreover VOC (i.e. styrene) and Ozone generated during printing operation can interact with each other building reactive oxidative products in form of gas or ultrafine particles which in turn can act as irritants $[4,5]$

Operation of printers and copiers generates paper and toner dust. Toners consist of very small particles of a thermoplastic polymer, usually a styrene-acrylate copolymer coated with black or coloured pigments. Black toners contain carbon black or more recently iron oxide as pigment, whereas colour toners contain various organic pigments. In addition, toners contain additives such as wax and silica and just small amounts of heavy metals such as lead nickel, chrome, mercury and cobalt that can be present as contaminant in toner mixtures. Finally it has been shown that the simple turn on of a printing device might generate an increase of fine and ultrafine dust, Siloxane emission generating from the heating of the fuser rolls are believed responsible for this UF particles emission [3,6-8].

Whereas the concentration of toner dust under normal printing condition is extremely low higher short-term emissions of toner dust may occur by accident, when changing a toner cartridge or when cleaning or repairing the printer. Adverse health effects from toner dust inhalation have been anecdotally reported $[9,10]$, epidemiological studies investigating the effect of toner dust are still on-going $[11,12]$.

\section{Case-Report}

A 40-year-old woman, employed as clerk in a local governmental

*Corresponding author: D'Alessandro Alessandra, Otto von Guericke University of Magdeburg, Section of Occupational Medicine, Leipziger Strasse 44, 39120 Magdeburg, Germany, Tel: +49 39167 15384; Fax: +49 39167 15083; E-mail: alessandra.dalessandro@med.ovgu.de

Received September 06, 2013; Accepted October 28, 2013; Published October 31,2013

Citation: Alessandro AD, Waldburg N, Boeckelmann I, Schreiber J (2013) Coughing from Copiers? Workplace Induced Chronic Cough after Exposure to Laser Printer Exhaust. J Allergy Ther 4: 154. doi:10.4172/2155-6121.1000154

Copyright: (C) 2013 Alessandro AD, et al. This is an open-access article distributed under the terms of the Creative Commons Attribution License, which permits unrestricted use, distribution, and reproduction in any medium, provided the original author and source are credited. 


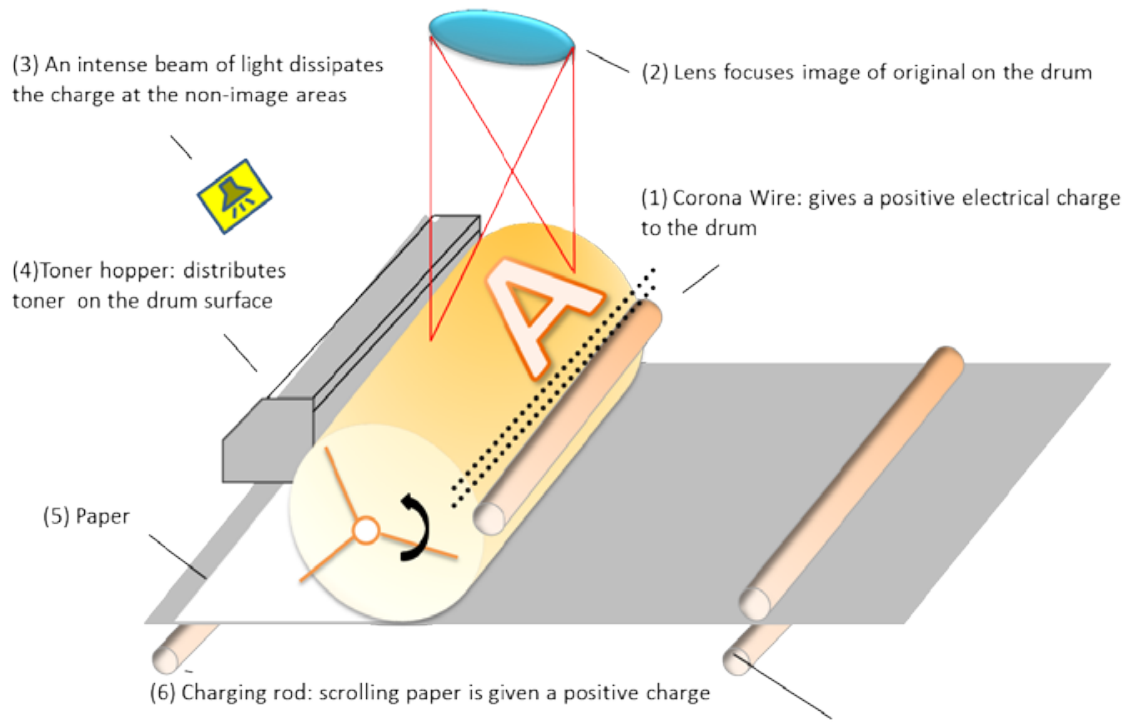

(5) Heater rollers: fuse the toner particle on the paper surface

Figure 1: Laser printer.

\begin{tabular}{|l|l|l|}
\hline Bronchoalveolar lavage & Pre-Exposition & Post-Exposition \\
\hline Cell count (Mill) & 228 & 95,9 \\
\hline Lymphocytes (\%) & 11 & 39 \\
\hline Neutrophilic-Granulocytes (\%) & 7 & 21 \\
\hline Macrophages (\%) & 81 & 39 \\
\hline Eosinophil Granulocyte & 1 & 1 \\
\hline CD4/CD8-Ratio & 1,3 & 1,5 \\
\hline
\end{tabular}

Table 1: BAL results before and after exposure.

administrative office, with no history of smoking or allergy, and without anticipated occupational exposure to allergens or toxic substances, presented with repeated episodes of intense non-productive cough while using a laser printer at work. She dated the onset of her initial symptoms to three years previous to her presentation, when the patient had been heavily exposed to toner dust while changing a cartridge because of malfunction of the cartridge lid. She did not complain of dyspnea or wheeze. Off-work or in vacation or while using inkjet printers, no cough or other respiratory symptoms were reported.

Physical examination, including an ear nose and throat assessment by a specialist, was unremarkable. Multiple laboratory studies were within normal limits, including differential blood count, antinuclear antibodies, antibodies subsets to nuclear antigens, total and IgE for common environmental allergens and angiotensin-converting-enzyme levels Blood gases as well as pulmonary function tests (spirometry, flow-volume loops, body plethysmography and diffusing capacity for carbon monoxide), allergy skin tests (including scratch test with native laser printer dust) were all normal. A bronchial provocation test with metacholine showed no sign of bronchial hyperreactivity. Exhaled nitric oxide was not measured. Chest radiography did not show any abnormality.

Fiberoptic bronchoscopy includingbroncho alveolar lavage (BAL) in the right middle lobe and biopsy of the bronchial mucosa was first performed after a 4 week period in which the patient was not exposed to any laser printer dust and was asymptomatic. The central bronchial system did not show any abnormality. The BAL cell composition and the CD4/CD8 ratio were normal (1.3) and a biopsy of the bronchial mucosa did not show any abnormality.

Four weeks later a provocation test was performed. The patient used a commercially available laser printer (KYOCERA ECOSYS FS-1030D) for one hour under supervision in an office with a room volume of $63 \mathrm{~m}^{3}$, under natural ventilation condition, both the toner used and the exposure condition were comparable with the usual workplace exposure condition. Working at the laser printer was associated with immediate paroxysms of cough. Chest auscultation was otherwise unremarkable. Pulmonary function tests including bronchial provocation with metacholine and blood gases, performed immediately after toner exposure did not change significantly. Bronchoscopy, with BAL and mucosal biopsy in the contra lateral lung, was repeated 48 hours after the provocation test. This time the BAL cellularity showed an increase of neutrophils and lymphocytes. The CD4/CD8 ratio was still normal (1.5). A biopsy of the bronchial mucosa revealed moderate signs of inflammation with infiltration of lymphocytes and few plasma cells. BAL results before and after exposure, are presented in Table 1.

We suggested to the patient a trial of avoidance to toner-dust. She is ever since free of symptoms.

\section{Discussion}

In this case report we show, to our knowledge for the first time that respiratory symptoms and a mixed lymphocytic and neutrophilic bronchial inflammatory reaction occur after working with a laser printer. That the changes in BAL cellularity and the histology correlate with the clinical symptom of cough but not with changes of lung function tests.

Chronic cough has been associated with lymphocytic infiltration of the bronchial wall [13] whereas we observed a mixed lymphocytic and neutrophilic reaction, compatible with an acute inflammatory response. Moreover the bronchoalveolar lavage and biopsy performed before exposure did not show inflammatory changes in the bronchial wall. The patient we describe did not develop asthma or bronchial 
Citation: Alessandro AD, Waldburg N, Boeckelmann I, Schreiber J (2013) Coughing from Copiers? Workplace Induced Chronic Cough after Exposure to Laser Printer Exhaust. J Allergy Ther 4: 154. doi:10.4172/2155-6121.1000154

Page 3 of 3

hyperreactivity, as demonstrated by the lack of response to metacholine and normal airway resistance that persisted also after the controlled exposure however, she developed cough, while and soon after working with the laser printer.

It is known that acute and chronic inhalational exposures to irritants may lead to chronic cough [13-17]. Laser printers emit fine and ultrafine particulate matter, Ozone, VOC and SVOC $[1,3]$ which, at appropriate concentrations, can act as irritants.

It has been proposed that in conditions where there is repeated irritant-induced airway epithelial injury and irritant-induced inflammation a persistent TRPs channel activation may occur leading to TRP pathy because of hyperactivity of TRP [18]. Although we did not perform immunohistochemistry staining with antibodies against the TRP protein we speculate that, the underlying pathophysiological event be an initial irritant-induced inflammation followed by persistent TRPs channel activation. Although we cannot indicate which component of the laser printer exhaust was responsible of the observed effect we conclude that, in symptomatic patients exposed to printer exhaust, an inflammatory reaction of the bronchial mucosa should be kept in mind.

\section{References}

1. Gesundheitliche Bewertung Nr. 014/2008 des BfR (2008) BfR schließt Arbeiten zur "Toner"-Problematik mit einer gesundheitlichen Bewertung möglicher Risiken durch Druckeremissionen ab 31

2. http://www.scientificamerican.com/article.cfm?id=how-does-a-photocopier-wo.

3. Gminski R, Mersch-Sundermann V (2006) Gesundheitliche Bewertung der Exposition gegenüber Tonerstäuben und gegenüber Emissionen aus Laserdruckern und Kopiergeräten -aktueller Erkenntnisstand. Umweltmed Forsch Prax 11: 269-300.

4. Wolkoff P, Wilkins CK, Clausen PA, Nielsen GD (2006) Organic compounds in office environments - sensory irritation, odor, measurements and the role of reactive chemistry. Indoor Air 16: 7-19.
5. Weschler CJ (2000) Ozone in indoor environments: concentration and chemistry. Indoor Air 10: 269-288.

6. Bake D, Moriske HJ (2006) Untersuchungen zur Freisetzung feiner und ultrafeiner Partikel beim Betrieb von Laserdruck-Geräten.

7. Tang T, Hurraß J, Gminski R, Mersch-Sundermann V (2012) Fine and ultrafine particles emitted from laser printers as indoor air contaminants in German offices. Environ Sci Pollut Res Int 19: 3840-3849.

8. Wensing M, Schripp T, Uhde E, Salthammer T (2008) Ultra-fine particles release from hardcopy devices: sources, real-room measurements and efficiency of filter accessories. Sci Total Environ 407: 418-427.

9. Gallardo M, Romero P, Sánchez-Quevedo MC, López-Caballero JJ (1994) Siderosilicosis due to photocopier toner dust. Lancet 344: 412-413.

10. Armbruster C, Dekan G, Hovorka A (1996) Granulomatous pneumonitis and mediastinal lymphadenopathy due to photocopier toner dust. Lancet 348: 690.

11. Kitamura H, Terunuma N, Kurosaki S, Hata K, Ide R, et al. (2009) Crosssectional study on respiratory effect of toner-exposed work in manufacturing plants, Japan: pulmonary function, blood cells, and biochemical markers. Hum Exp Toxicol 28: 331-338.

12. Terunuma N, Kurosaki S, Kitamura H, Hata K, Ide R, et al. (2009) Crosssectional study on respiratory effect of toner exposure. Hum Exper Toxicol 28 325-330.

13. Irwin RS, Ownbey R, Cagle PT, Baker S, Fraire AE (2006) Interpreting the histopathology of chronic cough: a prospective, controlled, comparative study. Chest 130: 362-370

14. Tarlo SM (2006) Cough: occupational and environmental considerations: ACCP evidence-based clinical practice guidelines. Chest 129: 186S-196S.

15. Tarlo SM (2000) Workplace respiratory irritants and asthma. Occup Med 15 471-484.

16. Groneberg DA, Nowak D, Wussow A, Fischer A (2006) Chronic cough due to occupational factors. J Occup Med Toxicol 1: 3.

17. Brooks SM, Bernstein IL (2011) Irritant-induced airway disorders. Immunol Allergy Clin North Am 31: 747-768, vi.

18. Brooks SM (2008) Irritant-induced chronic cough: irritant-induced TRPpathy Lung 186: S88-S93.
This article was originally published in a special issue, COPD: Epidemiology and New Therapeutics handled by Editor. Dr. A.B. Raja Chatteriee,

Wake

Forest University School of Medicine, USA 